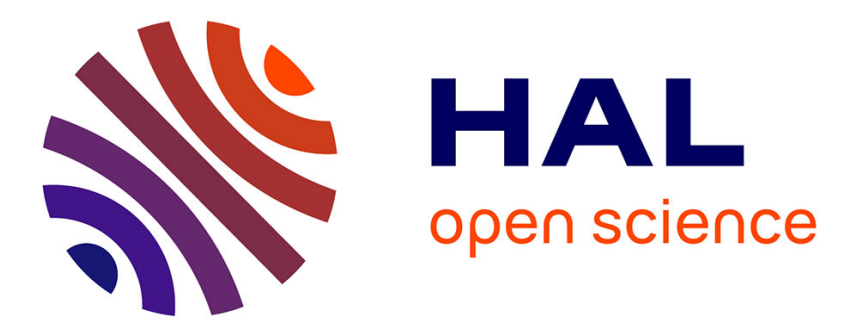

\title{
Towards Support for Strategic Decision Processes Using Enterprise Models: A Critical Reconstruction of Strategy Analysis Tools
}

\author{
Alexander Bock, Ulrich Frank, Arne Bergmann, Stefan Strecker
}

\section{To cite this version:}

Alexander Bock, Ulrich Frank, Arne Bergmann, Stefan Strecker. Towards Support for Strategic Decision Processes Using Enterprise Models: A Critical Reconstruction of Strategy Analysis Tools. 9th IFIP Working Conference on The Practice of Enterprise Modeling (PoEM), Nov 2016, Skövde, Sweden. pp.41-56, 10.1007/978-3-319-48393-1_4 . hal-01653509

\author{
HAL Id: hal-01653509 \\ https://hal.inria.fr/hal-01653509
}

Submitted on 1 Dec 2017

HAL is a multi-disciplinary open access archive for the deposit and dissemination of scientific research documents, whether they are published or not. The documents may come from teaching and research institutions in France or abroad, or from public or private research centers.
L'archive ouverte pluridisciplinaire HAL, est destinée au dépôt et à la diffusion de documents scientifiques de niveau recherche, publiés ou non, émanant des établissements d'enseignement et de recherche français ou étrangers, des laboratoires publics ou privés. 


\title{
Towards Support for Strategic Decision Processes Using Enterprise Models: A Critical Reconstruction of Strategy Analysis Tools
}

\author{
Alexander Bock ${ }^{1}$, Ulrich Frank ${ }^{1}$, Arne Bergmann ${ }^{2}$, and Stefan Strecker ${ }^{2}$ \\ 1 Research Group Information Systems and Enterprise Modeling, \\ University of Duisburg-Essen, Essen, Germany \\ alexander.bock@uni-due.de, ulrich.frank@uni-due.de \\ 2 Enterprise Modelling Research Group, University of Hagen, Hagen, Germany \\ arne.bergmann@fernuni-hagen.de, stefan.strecker@fernuni-hagen.de
}

\begin{abstract}
Strategic decision processes are traditionally thought to affect an organization's long-term success, motivating the development of strategy analysis tools. But ordinary strategy analysis tools have been criticized on several grounds, such as the neglect of organizational context and ill-defined concepts. This paper explores whether enterprise models can provide a richer foundation for strategic analysis, intending to lay the ground for the development of a modeling language. Specifically, the paper analyzes key concepts of traditional strategy analysis tools, reconstructs these concepts in the form of a meta model, and demonstrates integration potentials with enterprise models. The paper closes with implications and lessons learned for future research.
\end{abstract}

Key words: Enterprise modeling, domain-specific modeling languages, strategic decision processes, strategy analysis tools

\section{Introduction}

It is traditionally thought that "to forecast and provide means examining the future and drawing up the plan of action" is a prime responsibility of the manager [1, p. 5]. With the publication of Ansoff's Corporate Strategy [2] and Andrews' The Concept of Corporate Strategy [3], related processes have come to be placed predominantly under the heading of strategic planning and strategic decision processes. In the light of an on-going digital transformation, these processes seem more relevant than ever. New, sometimes disruptive technologies may emerge at any time, rapidly replacing established products. But while environmental contingencies motivate strategic planning, they also represent its key challenge. In the face of an uncertain future, the meaningfulness of detailed planning at a top level has long been questioned - to the extent that the 'Fall of Strategic Planning' has been posited two decades ago [4].

The complexity, contingency, and ambivalence of strategic problems motivate the use of approaches that facilitate the systematic analysis of a company's situation and the construction and assessment of strategic courses of action-without 
imposing too rigid constraints on future actions. Starting from this assumption, a variety of strategy analysis tools have been devised in the past decades. Examples include the Balanced Scorecard [5], the Five Forces framework [6], and Portfolio Analysis. However, while remaining popular, these tools exhibit remarkable shortcomings. For instance, important organizational context is neglected. This comes at a price of increased difficulty when interpreting a strategic plan and the danger of divergent interpretations. Furthermore, essential concepts (e.g., 'perspective' or 'activity') remain too ambiguous, underspecified, or even misleading. Finally, extant strategy analysis tools do not account for the peculiarities of information technology (IT), treating it largely as a black box.

Enterprise models provide detailed organizational context relevant to and necessary for strategic planning $[7,8]$. Specifically, enterprise models allow to identify enablers and inhibitors of strategic change in an organization at a detailed level, in particular concerning the interplay of business patterns and information systems. Thus, they provide a promising foundation to support strategic decision processes in a methodical way. However, even elaborate enterprise modeling methods such as ArchiMate [9], Multi-perspective Enterprise Modeling (MEMO) [8], or For Enterprise Modeling (4EM) [7] do not offer nuanced concepts to describe and (re-)assess corporate strategies, and they lack comprehensive support for the task of strategic planning. Some conceptual modeling methods to analyze strategic issues have been proposed (e.g., [10]). But these are not meant as extensions to comprehensive enterprise modeling methods.

The purpose of this paper is to prepare the design of a DSML in support of strategic planning using enterprise models. Specifically, the contribution of this paper is threefold. First, we analyze traditional strategy analysis tools and critically reconstruct their concepts. This approach is based on the assumption that before reshaping or developing new concepts, it is reasonable to consider and critically review what concepts are well-accepted in practice. Second, we demonstrate how the reconstructed concepts relate to, and can be integrated with, an existing enterprise modeling method. Third, we discuss prospects and limitations of the identified concepts and outline routes for future research.

The paper is structured as follows. In Sect. 2, we consider theoretical groundwork, before analyzing selected strategy analysis tools in Sect. 3. Key concepts of these tools are reconstructed in Sect. 4 , in which we also illustrate and discuss integration points with enterprise models. We provide closing remarks in Sect. 5.

\section{Theoretical Background: Strategies and Decisions}

In order to prepare our analysis and reconstruction of existing strategy analysis tools, this section provides a brief synthesis of theoretical arguments centering around the notions of 'strategy' and 'decision' in the literature.

The Notion of Strategy. One of the first works in management literature explicitly referring to the term 'strategy' was Strategy and Structure by Chandler [11]. Since then, a large body of literature on the subject emerged (e.g., 
[2], [12], [4], and [13]), producing a wide range of definitions of the term 'strategy'. Chandler, for instance, defines strategy as "the determination of the basic longterm goals and objectives of an enterprise and the adoption of courses of action and the allocation of resources necessary for carrying out these goals" [11, p. 13]. For Hofer, a strategy is "concerned with the development of a viable match between the opportunities and risks present in the external environment and the organizations capabilities and resources for exploiting these opportunities" $[14$, p. 3]. In these interpretations, the term strategy is mostly prescriptive in nature, and based on the presumption of a formal, systematic planning process. Further, these definitions indicate a core set of domain-specific terms - including 'goal', 'resource', and 'external environment' - without which it seems hard to communicate about the concept of strategy.

However, the traditional view of strategic planning has been subject to considerable critique (see, e.g., [4, pp. 110-111]). In later work, therefore, varied other research branches emerged in the literature. One branch, although still accepting basic assumptions of traditional planning, pays less attention to a formalized planning process and more strongly focuses on the contents of a strategy (such as competition, resources, and competencies; e.g., [12]). Another branch, for example, is concerned with how strategies actually form. This branch, descriptive in nature, places emphasis on concepts like 'organizational learning' or 'strategic thought' (e.g., [15], [16] and [17]). In line with the indicated variety, a paradigm change is observable since the 1990s, from the belief in one 'true' definition towards a pluralistic view where strategy is seen as a multi-dimensional construct whose understanding depends on the perspective(s) taken [18].

Strategic Decision Processes. Although there are many views of what a 'strategy' entails in particular, one of the most common ways to frame the processes in which strategies are devised is as strategic decision processes (see, e.g., [19]). Just as for the concept of 'strategy', different views on decisions have been advanced. A traditional view, found in major parts of decision research, states that the "one essential element of a decision is the existence of alternatives [...], a choice to make" [20, p. 2]. In this view, the "rational" decision maker's task is often seen to consist in choosing among given alternatives so that given goals are attained to the highest degree possible (see, e.g., [21, pp. 79-109]).

However, it follows from the above account of 'strategy' that a purely choicecentric view is incomplete. First, it disregards the observation that often, in considering strategic courses of action, there are no or only few 'alternatives' given at the outset (e.g., [22, pp. 251, 255-256] [2, pp. 15-16]). Instead, there is a need to search for, or construct, possible alternatives (e.g., [2, pp. 15-16] [23, p. 58]). This is considered in a process view of decision making. In this view, it has been observed that strategic decision processes are typically time-consuming and highly fragmented [19, p. 46] [24, pp. 203-205], "taking years and involving many members of the organization" [23, p. 60]. In particular, the construction of alternatives has been recognized as important; "a great deal of effort goes into the development of solutions, especially design activity, since solutions must often be custom made" [23, p. 61]. In this connection, research has also high- 
lighted the close connection between organizational decision making and problem solving (e.g., [25, pp. 855-856] [26, p. 321]). A problem solving view emphasizes that decision processes are largely concerned with analyzing, constructing, interpreting, and revising representations of the (problem) situation in question [26, p. 321-324]. Specifically, it has been suggested that strategic problems are "ill-structured, nonroutine, and complex" [27, p. 379-380]. Similarly, strategy has also been claimed to be a 'wicked' problem, which "has innumerable causes, is tough to describe, and doesn't have a right answer" [28, p. 100]. In sum, (strategic) decision processes need to incorporate, rather than presuppose, the construction of problem definitions, goals, and alternatives [26, p. 321-324].

\section{Strategy Analysis Tools: Overview and Assessment}

As strategic decision-making requires to structure and interpret rich and ambiguous (problem) situations, it comes at no surprise that numerous analysis tools have been proposed to support this task (for an overview, see, e. g., [29]). In this section, we conceptually analyze five widely discussed and applied tools to identify their inherent domain-specific concepts. This study is meant to help prepare the design of a future DSML in which refined or extended versions of the identified concepts might appear to support strategic decision processes.

Taking into account studies on the dissemination of analysis tools in practice [30] [31] [32], five tools have been selected as a starting point: SWOT analysis, Portfolio Analysis, the Balanced Score Card, Porter's Value Chain, and his Five Forces framework. The selection is neither exhaustive nor representative, but the selected tools have certainly received widespread recognition and are assumed to indicate concepts that are in common use in the domain of discourse. Following a synoptic overview of each strategy analysis tool that outlines its purpose and key concepts (Sect. 3.1), we assess the suitability of the tools and their concepts with regard to devising a DSML (Sect. 3.2). To improve clarity, identified key concepts will appear in italics. Common visualizations for each tool are shown in Fig. 1, alongside semantic nets summarizing the distilled key concepts.

\subsection{Synoptic Overview of Selected Strategy Analysis Tools}

SWOT Analysis. Although its origin remains unclear, SWOT analysis started to gain traction in the 1960s with its inclusion in textbooks at Harvard Business School [33]. SWOT analysis is based on a simple idea: to start devising basic strategic directions, it is useful to assess the internal and external context of the firm in a contrasting way [34, p. 342]. For this purpose, SWOT analysis builds on a small number of key concepts. 'Strength' and 'Weakness' are intended to capture abilities and limitations of a company and are interpreted as 'Internal Factors'. 'Opportunity' and 'Threat' serve to analyze a firm's environment with respect to either new possibilities or obstructions for current ways of doing business. They are interpreted as 'External Factors'. Implicit in this structure is also 
the idea of a 'Positive Valence' or a 'Negative Valence' ascribed to each factor. SWOT analysis is typically visualized in the form of a $2 \times 2$ grid (Fig. 1, pt. 1a).

Portfolio Analysis is used to consider the allocation of resources to different strategic areas [34, pp. 347-349]. At its core, it is even more generic than SWOT analysis. In essence, portfolio analysis advises to place concrete 'Values' for a 'Strategic Object' of a 'Portfolio' along two specific 'Dimensions' (see Fig. 1, pt. 2a). This general idea can be illustrated by means of one of its more popular variants, the Boston Consulting Group Matrix (BCG Matrix) [34, pp. 353-363]. The 'Strategic Object' of analysis here is a strategic business unit (SBU) or a product. The first dimension is market growth, supposed to express the attractiveness of a 'Market'. The second dimension is relative market share, assumed to represent the competitiveness of the 'Strategic Object'. The BCG approach (as other variants of portfolio analysis) advises to divide the overall portfolio area into different 'Quadrants', where each 'Quadrant' is linked to a different 'Norm Strategy' (an idealized recommended strategy formulation) [34, pp. 353-363].

The Balanced Scorecard (BSC) has been developed by Kaplan and Norton as a "mechanism for strategy implementation" [35, pp. 37-38]. The BSC is based on several assumptions $[5,36]$. First, corporate strategy and vision are essentially considered in terms of interlinked 'Objectives'. To assess the attainment of ' $\mathrm{Ob}$ jectives', it is suggested to define (quantifiable) 'Measures' for all objectives [5]. Second, it is assumed that a strategy can (and should) cover objectives assigned to different 'Perspectives'. An essential contribution of the BSC is the differentiation of financial and non-financial perspectives. The original BSC includes four perspectives: 'Financial', 'Customer', 'Internal Processes', and 'Learning $\& 6$ Growth'. Third, the BSC assumes 'causal' relationships among objectives in the sense that the attainment of 'Objectives' from non-financial perspectives is assumed to contribute to achieving 'Objectives' in the financial perspective, meant to capture organizational performance [34, p. 221]. In a later version [35], two further concepts are added: 'Targets' describe concrete values to be reached for a given 'Measure', while 'Initiatives' describe courses of action intended to achieve 'Targets'. Fig. 1, pt. 3a, shows a typical visualization of the BSC.

The Value Chain (VC) was proposed by Porter [37]. Its main objective is to assist in identifying (possible) competitive advantages of a firm by focusing on its presumed value creation [34, p. 305]. The main concept 'Value Chain' is decomposed into so-called 'Activities'. These represent a functional abstraction; temporal aspects are not accounted for. 'Activities' are distinguished into 'Primary Activities' (directly contributing to value creation) and 'Support Activities' (needed to perform primary activities) [34, p. 307]. The prototypical definition of a Value Chain includes a fixed set of five 'Primary Activities' and four 'Support Activities', shown in Fig. 1, pt. 4a. When using a 'Value Chain', it is suggested to reflect on how each 'Activity' is, and could possible be, decomposed in more detail. In line with Porter's general positioning view [37], competitive advantages are hypothesized to result from how the performance of 'Activities' compares to competitors (or an industry average) in the same market [34, p. 308]. The configuration of all 'Activities', finally, is assumed to affect the overall 'Margin'. 


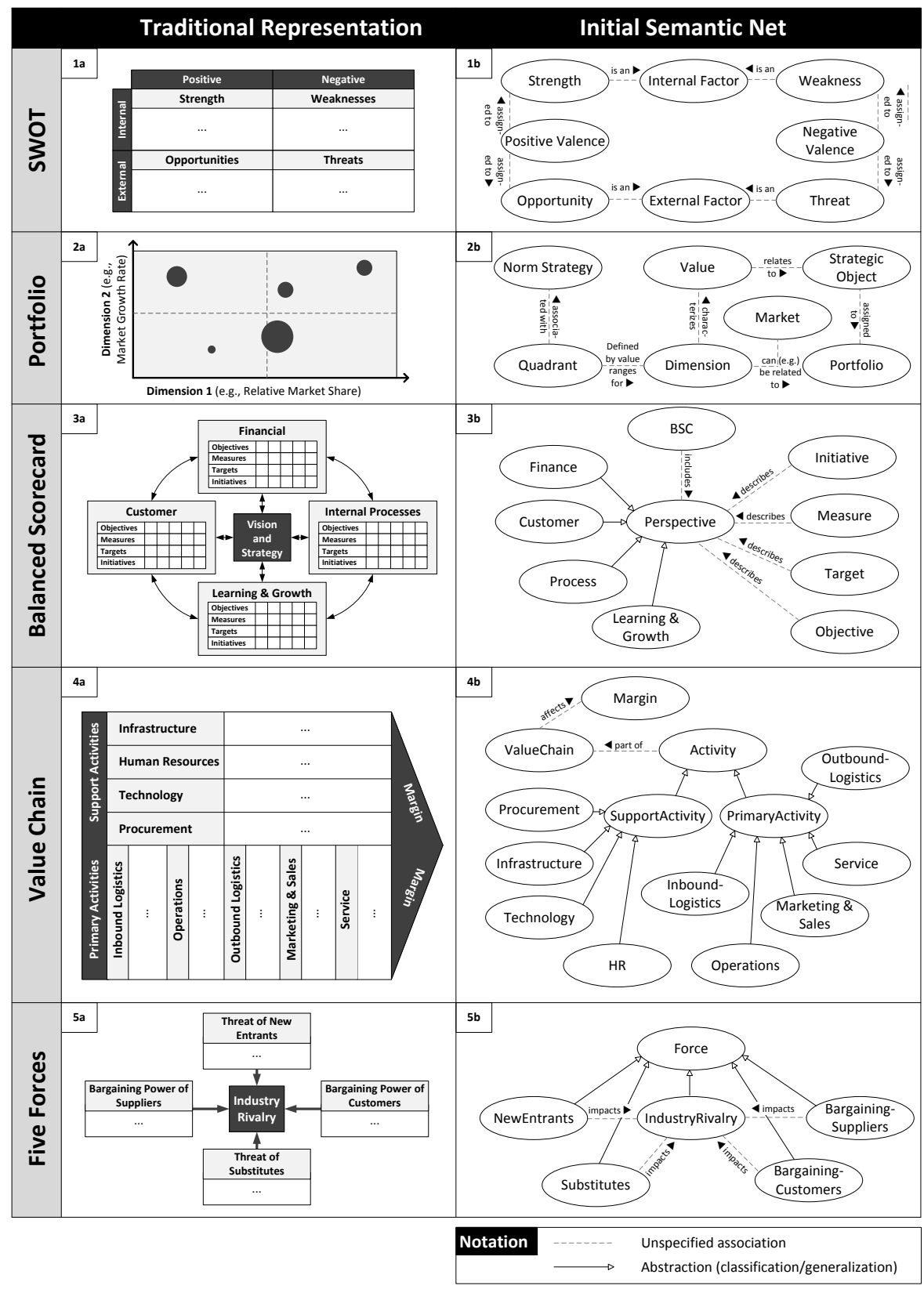

Fig. 1. Strategy analysis tools: Traditional representations and initial semantic nets 
The Five Forces framework has also been proposed by Porter [6,38]. In contrast to the Value Chain, this framework more explicitly concentrates on the industry environment. The basic assumption is that an interplay of five forces determines an industry's intensity of competition and, as a result, potentials for generating profits [34, p. 311]. Accordingly, the core concept is 'Force'. More specifically, Porter posits the existence of five kind of forces $[6,38]$ : (1) The threat of 'New Entrants' (affected by, e.g., market entry barriers like needed production technologies); (2) the threat of 'Substitutes' (affected by the availability of alternatives for a firm's products or services, like new technologies); (3) the 'Bargaining Power of Suppliers' and (4) the 'Bargaining Power of Customers' (affected by, e.g., the number of possible suppliers or customers, respectively), and (5) 'Industry Rivalry' (affected by the combined strength of the other forces) [38]. Considering these forces, Porter suggests to position a "company where the forces are the weakest" [6, p. 24]. Porter also provides a list of factors assumed to influence the strength of the different forces, alongside various guidelines on how to react to certain force constellations. When using this tool, it is customary to draw on a representation as shown in Fig. 1, pt. 5a [6].

\subsection{Assessment: Conceptual Suitability for Enterprise Modeling}

All of the analysis tools portrayed above have been discussed in the literature for long. In these discussions, they have been subject to fundamental criticism. Generally, they have been criticized for simplifying a complex 'strategic problem' (cf. Sect. 2) to an unacceptable degree by fading out important contextual aspects $[39,40]$. Fundamental criticism also pertains to questionable epistemological assumptions underlying the tools. For instance, it is seen as a misconception to assume cause-and-effect relationships between financial and non-financial measures, as is suggested by [5,35] (for a discussion, see [41]). Beyond such general criticism, devising modeling concepts in the context of enterprise modeling comes with specific requirements concerning conceptual clarity. Below, therefore, we assess the suitability of the analysis tools' specification of key concepts as well as the proposed (or missing) abstractions in respect of the design of a DSML.

It applies to all analysis tools that key concepts are not precisely, i.e., unequivocally, let alone formally, defined. The intended meaning of concepts as well as their intended usage in the context of an analysis tool is typically described in natural language and illustrated by a few examples which leaves room for unintended interpretation. Important concepts such as 'value' or 'strength' are not defined at all, consequently referring to a colloquial understanding. Resolving the resulting ambiguities during conceptual reconstruction is not trivial, not only because of careless concept definitions and the difficulties resulting from reconstructing implicit (potentially intended) meaning from natural language descriptions, but also because of the peculiarities of a contingent subject.

It is characteristic for the studied tools that their core concepts reflect the perspective of top management, that is, a high level of abstraction where most details are faded out on purpose. However, oftentimes it is important to develop a more detailed appreciation of selected aspects. For example, when reflecting 
about possible (strategic) paths to achieve desired goals, it is necessary to consider actors, resources, IT, and related aspects. Also, to develop a grounded assessment of internal processes, it oftentimes appears mandatory to analyze aspects of the control flow or the resource consumption. However, none of the investigated tools provides concepts for supporting analyses at that level of detail. Moreover, none of the tools provides an elaborate conception of the IT infrastructure which, if it is accounted for at all, is represented as a black box.

A particular challenge for conceptual reconstruction of the studied tools results from a lack of explicit abstraction. For example, it remains unclear whether 'primary activity' and 'support activity' in the Value Chain are meant to be instances of a meta concept 'activity' or rather sub-concepts. Furthermore, concepts such as 'objective', 'activity', and 'dimension' are introduced without defining a level of classification. For specifying a DSML, however, it is essential to make an informed design decision at which language level to provide a concept (e.g., at type, meta type, or even a higher level). Arriving at such a decision is not trivial for many of the identified concepts (e.g., what is an instance of a 'dimension', and how can a type of a 'dimension' be meaningfully specified?).

\section{A Conceptual Reconstruction in the Context of Enterprise Modeling}

The previous analysis has brought to the fore a number of concepts for strategic analyses. The discussion has also indicated a number of shortcomings of the considered tools. To prepare the development of a DSML to support strategic decision processes in future work, we aim to reconstruct and integrate the distilled concepts in a meta model in this section. In doing so, we also intend to place the reconstructed concepts in the context of an existing enterprise modeling method, seeking to outline integration possibilities with concepts already available. This exercise is intended to help clarify two questions. First, we wish to analyze whether embedding concepts of selected strategy analysis tools in traditional enterprise modeling languages can provide a meaningful basis to support strategic decision processes. Second, we would like to examine whether the design of language concepts for strategic analyses is associated with specific challenges.

We will first describe the procedure followed (Sect. 4.1), before presenting the meta model (Sect. 4.2). Following this, we will discuss resulting insights and point out prospects and challenges for a future development of a DSML (Sect. 4.3). To illustrate the integration possibilities with existing enterprise modeling methods, we will draw on a method for multi-perspective enterprise modeling (MEMO) [8]. This enterprise modeling method is selected because it has been found to feature an especially comprehensive set of modeling concepts [42].

\subsection{Background and Procedure}

In order to arrive at a meta model that couches the identified concepts in the context of enterprise modeling, we conducted several steps. In a first step, we 
prepared a straightforward representation of identified concepts using semantic nets (Fig. 1, part b). Subsequently, we merged the initial semantic nets into a single coherent semantic net and refined it successively by adding detail, removing conceptual redundancies, and identifying abstractions (e.g., generalizations). The final semantic net served as a foundation for creating a meta model.

To specify the meta model, we used the Flexible Meta-Modeling and Execution Language $\left(F M M L^{x}\right)$ [43]. This language features a recursive language architecture, enabling an arbitrary number of classification levels. It also includes 'intrinsic features' to define (meta) attributes, operations, and associations on $M_{n}$ that are to be instantiated at level $M_{m}$, where $m<n-1$. Intrinsic features are visually represented by small black squares attached to model elements. For example, an intrinsic feature reading ' 0 ' (e.g., attached to an attribute at $M_{2}$ ) states that the attribute is to be instantiated at level $M_{0}$ only.

In the design of the meta model, we were immediately confronted with a number of challenges. First, the design of language concepts generally requires a decision as to whether a concept should be part of the language (usually, at $M_{2}$ ) or rather be specified with the language (usually, at $M_{1}$ ). It does not come as a surprise the level of classification seems contingent for most reconstructed concepts. Furthermore, none of the original concepts was defined with properties that could directly be mapped to attributes. This required us to conceive of possible useful (example) attributes. The next section will present preliminary design solutions, identifying implications for future work (discussed in Sect. 4.3).

\subsection{Meta Model}

As a result of interpreting and refining the semantics nets, a meta model has been devised that incorporates the concepts extracted from the analysis tools and integrates them with concepts of MEMO. The meta model is shown in Fig. 2. The reconstructed concepts have been assigned to four perspectives, indicated by the gray colored boxes. In addition, blue colored areas are found in which MEMO concepts are placed that constitute possible integration points for the perspective in question (an overview of MEMO concepts is found in [8]). Each perspective encompasses a set of meta types $\left(M_{2}\right.$; elements with a black colored header), reconstructing concepts of one or several analysis tools. To illustrate how concepts could be enriched as part of a future language, we have defined a number of example attributes. Further, for most meta types, example instantiations at type level $\left(M_{1}\right.$; elements with a white colored header) and instance level $\left(M_{0}\right.$; gray colored header) have been added to aid the interpretation of the meta types. This also exemplifies the value of the intrinsic features of the $F M M L^{x}$, enabling to clearly define at which level (meta) model elements are to be instantiated.

The first perspective is Internal and External Strategic Assessment, summarizing concepts from SWOT analysis and the Five Forces framework. Central abstractions here include the abstract concept 'StrategicFactor' $\left(M_{2}\right)$ and its two specializations 'ExternalStrategicFactor' and 'InternalStrategicFactorAssessment'. 'Opportunity' and Threat' are specializations of 'ExternalStrategicFactor'. Because the Five Forces can be regarded as possible instantiations of 'Threat' and 
'Opportunity', they do not appear as dedicated concepts in the meta model. For instance, a 'Threat' can be instantiated into a 'New Entrant' on $M_{1}$ and a concrete entrant on $M_{0}$ (see Fig. 2). The concepts 'Strength' and 'Weakness' have been condensed into the concept 'InternalStrategicFactorAssessment', located on $M_{2}$. This concept is supposed to serve as an unitary way of evaluating whether elements in an enterprise are regarded as a 'Strength' or a 'Weakness'. The auxiliary type 'OrdAssess', used here and in other concepts, is meant to provide an ordinary assessment for such evaluations (e.g., using values from 'low' to 'high'). The perspective Strategic Objects pools concepts drawn from portfolio analysis, most importantly 'Portfolio' and 'StrategicObject'. In this conceptualization, a 'Product' or 'SBU' would result as an instantiation at $M_{1}$, while a specific product (e.g. 'TBO-S4') would be located on $M_{0}$. Rather than relying on a generic concept 'Dimension', a domain-specific MEMO concept, 'Indicator', is used to arrange 'StrategicObject' for purposes of comparison. Furthermore, portfolio analysis has prompted us to include the concept 'Market', as this concept is often referenced in dimensions to consider 'StrategicObjects'. However, because a 'Market' is closely related to external factors, it is placed in the perspective above. The third perspective is called Goals and Initiatives. This perspective solely includes concepts that have been reconstructed from the BSC. Similarly, the fourth perspective Organizational Structure and Processes contains concepts reconstructed from the Value Chain. Note that 'Activity' and 'SubActivity' are not identical with the concept of a 'BusinessProcess'. They instead represent a functional abstraction, such as 'Outbound Logistics' (at level $M_{1}$; see Fig. 2).

Importantly, for concepts from all perspectives, integration points with existing MEMO concepts have been identified. These appear in the blue colored areas. For example, goals occupy a central role in the meta model, representing the prime integration point for the perspective advocated by the BSC. The corresponding MEMO language GoalML provides various concepts that can be mapped directly to BSC concepts (e.g., a BSC 'Measure' corresponds to a 'SituationalAspect' in GoalML). Of course, the full MEMO language also provides a richer way of describing goals than is enabled by the BSC. Similarly, there are MEMO languages to describe organizational structures and processes (bottom perspective) and decision processes (second perspective). More generally, when intending to assess reference objects of varied nature (top perspective), a comprehensive enterprise modeling method would enable to integrate the assessment concepts with diverse concepts to describe elements in an organization. This could be realized using a placeholder concept such as 'ReferenceObject' (see Fig. 2, top left). For present purposes, MEMO concepts are linked to the reconstructed concepts only by means of a green colored placeholder association. This association expresses that a correspondence or relevance exists, but it does not specify how it should be specified in more detail as part of a future DSML. For example, it can be found that a 'SubActivity' (bottom perspective in Fig. 2) is generally related to MEMO concepts describing organizational structures (e.g., 'OrganizationalUnit') and dynamic abstractions (e.g., 'BusinessProcess'). Disentangling these relations would imply considering associations of different nature, 
such as responsibility and decomposition relations, which further indicates the level of detail an enterprise modeling context would offer for strategic analyses. Finally, this same point is also stressed by the fact that the various MEMO languages are integrated (see the links between the blue colored areas). In consequence, the integration of strategy analysis concepts with enterprise modeling concepts also establishes a closer connection between the original strategy concepts, potentially enabling a richer way of thinking about the problem domain.

\subsection{Discussion: Lessons Learned and Implications}

The meta model in the previous section has shown that enterprise modeling in fact provides a rich conceptual framework into which strategy analysis concepts can be embedded in meaningful ways. Below, we discuss key insights and implications for future research that have emerged during this conceptual study.

Implicitness of the Strategy Concept. It is an interesting observation that although all considered tools are intended to aid strategic reflections in one way or another, no tool introduces an explicit and clear concept of 'Strategy'. In consequence, when intending to design a DSML for strategic support, it needs to be clarified whether it makes sense to specify a distinct 'Strategy' modeling concept at all or whether strategy should be regarded as an abstract notion that emerges from a set of other modeling concepts. This is related to the next issue.

Conveyed Perspectives. While no considered tool provides an explicit strategy concept, all of them, by virtue of their tool-specific concepts, convey a specific notion of what is relevant for strategizing. In general, it can be concluded that many of these concepts are domain-specific in nature. This contrasts with classical general-purpose decision modeling approaches, which exclusively provide generic concepts like 'alternative' (see [44]). Two more specific points follow. First, in line with the theoretical strategy discourse (cf. Sect. 2), it appears that strategy can in fact be regarded as a multi-perspective construct, irreducible to a single real-world aspect. Using Berger and Luckmann's words, strategy might be understood as "an object of thought" which "becomes progressively clearer with this accumulation of different perspectives on it" [45, p. 22]. Second, when thinking about support for strategic decision processes, it follows that each tool will direct attention at certain real-world aspects and of necessity neglecting others. In fact, this is an important pitfall inherent in model-based decision aids in general (see [46]). The practical implications are significant because, as has been discussed in Sec. 2, problems considered in strategic decision processes are in need of constant (re-)interpretation and (re-)formulation. Overreliance on single tools might thus lead to a neglect of important aspects (for example, a Value Chain will by definition not be able to systematize strategic goals). In consequence, researchers should devote attention to a modeling language design that fosters a reflective account of multiple perspectives on strategy and and strategic problems. At the same time, language concepts for different perspectives should nonetheless be integrated - to be able to analyze dependencies among them.

Significance of 'Qualitative' Aspects. As a further issue, many concepts in strategic planning seem to resist a convincing characterization through at- 


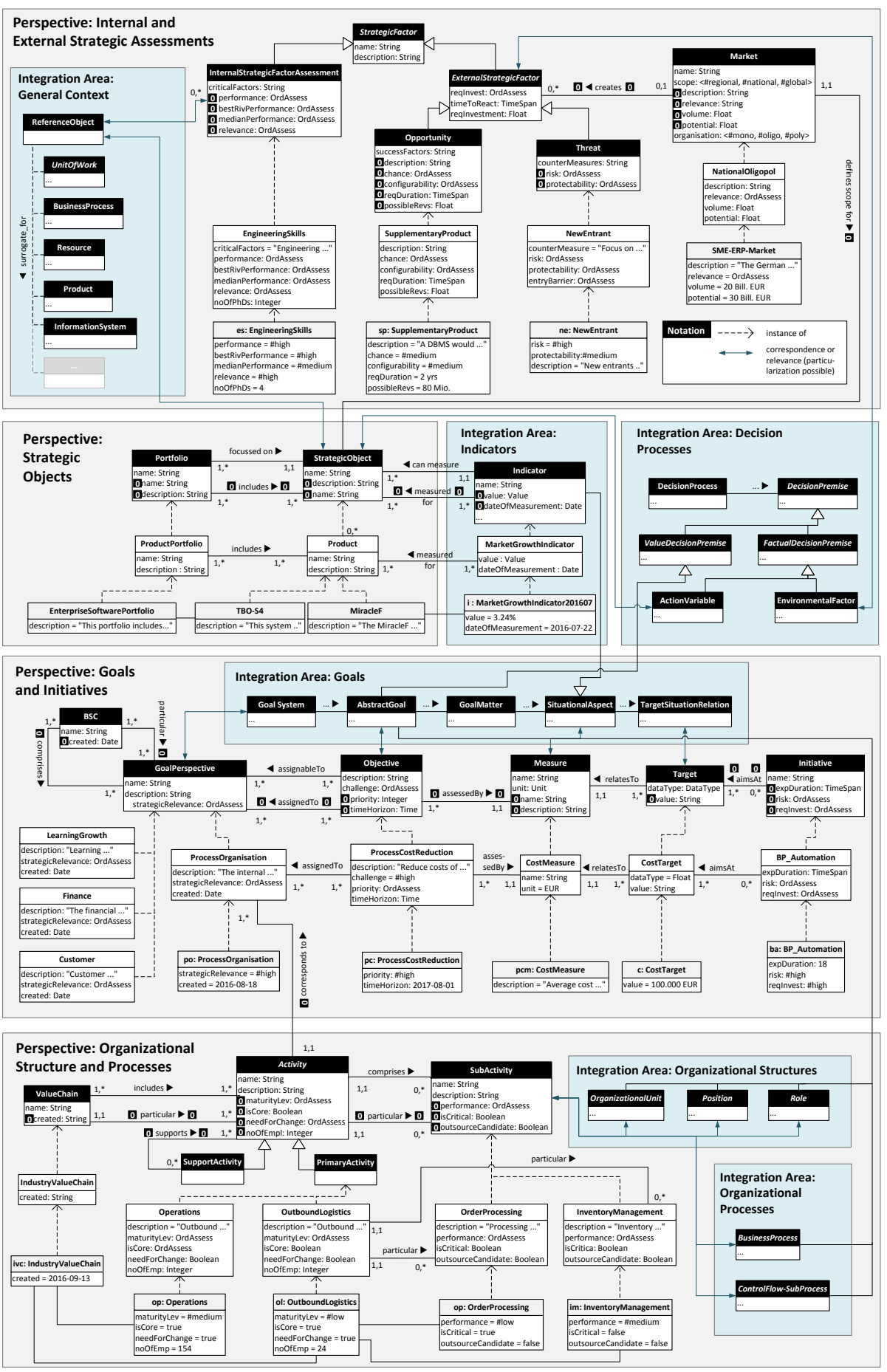

Fig. 2. Meta model including reconstructed strategy concepts 
tributes. This seems to occur because, from an ontological view, these identified concepts relate to qualitative judgments rather than to (real-world) objects whose state can be distinguished. When considering the meta model (Fig. 2), this is reflected in the many attributes with the data type 'OrdAssess', which is supposed to enable a judgment on an ordinal scale. With respect to language design, the issue suggests to develop conceptual means that stimulate a critical review of values assigned to evaluative attributes to avoid misleading models.

Need for Theoretical Reconciliation and Clarity. The analysis has shown that any attempt to design a DSML for supporting strategic reflections needs to conduct significant conceptual and theoretical groundwork in advance. First, this relates to the inherent conceptual vagueness of the domain (cf. Sect. 2 and 3.2). Beyond the examples considered in the meta model (Sect. 2), it would be necessary to clarify a number of further key terms in the domain (e.g., 'strategic plan'). A second implications concerns the clarification of theoretical claims. It is important to critically consider to what extent theoretical hypotheses in the strategy literature should be accepted for the desired modeling language.

Tool support. Finally, the meta model indicates how tools for enterprise modelling could be enhanced with components for strategic planning. For this purpose, the multilevel approach used to specify the meta model seems to be especially promising. Since the underlying architecture allows for a common representation of models and code [43], it can be used to integrate an enterprise modeling environment with enterprise software. Such a 'self-referential enterprise system' [47] could enable the runtime monitoring of strategy execution. This would, however, first require to tackle the above-indicated challenges for the development of a comprehensive DSML to support strategic reflections.

\section{Conclusions}

Strategic decision processes are thought to significantly affect an organization's long-term success, motivating the development of strategy analysis tools. In this paper, we have conducted a conceptual analysis of popular practical tools, reconstructing their key concepts in the form of a meta model and exploring potentials for the integration with enterprise modeling. The study has yielded several contributions. The presented meta model outlines how enterprise modeling could be enriched with concepts for strategic planning, while conversely showing a way of augmenting strategy analysis tools with relevant context. Furthermore, the analysis has revealed a number of challenges as an orientation for the future design of a DSML to aid strategic decision processes. Our future research agenda covers several aspects. First, we will (re-)investigate and expand the outlined integration potentials between strategy analysis tools and enterprise modeling in-depth. Second, we will conduct a more comprehensive requirements analysis for a DSML to support strategic planning, considering both the body of theoretical work as well as practical use case scenarios for strategic analysts, managers, and consultants. Finally, we will investigate the design of software tools to analyze and simulate possible paths for strategic development using enterprise models. 


\section{References}

1. Fayol, H.: General and Industrial Management. Pitman, London (1949)

2. Ansoff, H.I.: Corporate Strategy: An Analytic Approach to Business Policy for Growth and Expansion. McGraw-Hill, New York (1965)

3. Andrews, K.R.: Concept of Corporate Strategy. Richard D Irwin (1987)

4. Mintzberg, H.: Rise and Fall of Strategic Planning. Free Press, New York (1994)

5. Kaplan, R.S., Norton, D.P.: The balanced scorecard - measures that drive performance. Harvard Business Review 70(1) (1992) 71-79

6. Porter, M.E.: The five competitive forces that shape strategy. Harvard Business Review (1) (2008) 23-40

7. Sandkuhl, K., Stirna, J., Persson, A., Wißotzki, M.: Enterprise Modeling: Tackling Business Challenges with the 4EM Method. Springer, Berlin, Heidelberg (2014)

8. Frank, U.: Multi-perspective enterprise modeling: Foundational concepts, prospects and future research challenges. Software and Systems Modeling (2013)

9. The Open Group: ArchiMate 2.0 Specification: Open Group Standard. The Open Group Series. Van Haren, Zaltbommel (2012)

10. Horkoff, J., Barone, D., Jiang, L., Yu, E.S., Amyot, D., Borgida, A., Mylopoulos, J.: Strategic business modeling: representation and reasoning. Software \& Systems Modeling 13(3) (2014) 1015-1041

11. Chandler, A.D.: Strategy and Structure. MIT Press (1962)

12. Porter, M.E.: Competitive Advantage. Free Press (1985)

13. Kaplan, R.S., Norton, D.P.: Strategy maps: Converting intangible assets into tangible outcomes. Harvard Business School Press, Boston (2004)

14. Hofer, C.W.: Some preliminary research on patterns of strategic behavior. In: Academy of Management Proceedings. (1973) 46-54

15. Huff, A.S.: Mapping Strategic Knowledge. Thousand Oaks (2002)

16. Reger, R.K., Huff, A.S.: Strategic groups: A cognitive perspective. Strategic Management Journal 14(2) (1993) 103-123

17. Barr, P.S., Stimpert, J.L., Huff, A.S.: Cognitive change, strategic action, and organizational renewal. Strategic management journal 13(S1) (1992) 15-36

18. Cummings, S.: Strategy: past, present, future. In: The Sage handbook of new approaches in management and organization. SAGE, Los Angeles 184-194

19. Harrison, E.F.: A process perspective on strategic decision making. Management Decision 34(1) (1996) 46-53

20. Kirkwood, C.W.: Strategic Decision Making: Multiobjective Decision Analysis with Spreadsheets. Wadsworth, Belmont (1997)

21. Simon, H.A.: Administrative Behavior: A Study of Decision-Making Processes in Administrative Organization. 3 edn. Free Press, New York (1976)

22. Mintzberg, H., Raisinghani, D., Théorêt, A.: The structure of unstructured decision processes. Administrative Science Quarterly 21(2) (1976) 246-275

23. Mintzberg, H.: The Structuring of Organizations: A Synthesis of the Research. Prentice-Hall, Englewood Cliffs (1979)

24. Becker, A.: Rationalität strategischer Entscheidungsprozesse: Ein strukturationstheoretisches Konzept. Deutscher Universitätsverlag, Wiesbaden (1996)

25. Lang, J.R., Dittrich, J.E., White, S.E.: Managerial problem solving models: A review and proposal. Academy of Management Review 3(4) (1978) 854-866

26. Dery, D.: Decision-making, problem-solving and organizational learning. Omega 11(4) (1983) 321-328 
27. Dean, Jr., J.W., Sharfman, M.P.: Does decision process matter? a study of strategic decision-making effectiveness. Acad. of Manag. Journal 39(2) (1996) 368-392

28. Camillus, J.C.: Strategy as a wicked problem. Harv. Bus. Rev. 86(5) (2008) 98-106

29. Grant, R.M.: Contemporary Strategy Analysis. 9 edn. Wiley, Chichester (2016)

30. Stenfors, S., Tanner, L., Haapalinna, I.: Executive use of strategy tools: Building shared understanding through boundary objects. In: Frontiers of E-Business Research 2004 (Proceedings). (2004) 635-645

31. Clark, D.N.: Strategic management tool usage: a comparative study. Strategic Change 6(7) (1997) 417-427

32. Gunn, R., Williams, W.: Strategic tools: an empirical investigation into strategy in practice in the uk. Strategic Change 16(5) (2007) 201-216

33. Learned, E.P., Christensen, R.C., Andrews, K.R., Guth, W.D.: Business Policy Text and Cases. 1 edn. Richard D. Irwin, Inc (1969)

34. Macharzina, K., Wolf, J.: Unternehmensführung: Das internationale Managementwissen: Konzepte - Methoden - Praxis. 7 edn. Gabler, Wiesbaden (2010)

35. Kaplan, R.S., Norton, D.P.: The balanced scorecard: translating strategy into action. Harvard Business Press (1996)

36. Kaplan, R.S., Norton, D.P.: Putting the balanced scorecard to work. Harvard Business Review (5) (1993) 134-147

37. Porter, M.E.: The value chain and competitive advantage. In Barnes, D., ed.: Understanding business. Understanding business behaviour. Routledge, London (2001) 50-66

38. Porter, M.E.: Competitive strategy: Techniques for analyzing industries and competitors. Free Press, New York (1980)

39. Derkinderen, F.G., Crum, R.L.: Pitfalls in using portfolio techniques? assessing risk and potential. Long Range Planning 17(2) (1984) 129-136

40. Helms, M.M., Nixon, J.: Exploring swot analysis-where are we now? a review of academic research from the last decade. J. Econ. Manag. 3(3) (2010) 215-251

41. Norreklit, H.: The balance on the balanced scorecard a critical analysis of some of its assumptions. Management accounting research 11(1) (2000) 65-88

42. Bock, A., Kaczmarek, M., Overbeek, S.J., Heß, M.: A comparative analysis of selected enterprise modeling approaches. In Frank, U., Loucopoulos, P., Pastor, Ó., Petrounias, I., eds.: The Practice of Enterprise Modeling. Volume 197 of LNBIP. Springer, Heidelberg and New York (2014) 148-163

43. Frank, U.: Multilevel modeling: Toward a new paradigm of conceptual modeling and information systems design. Bus. and Inf. Systems Eng. 6(6) (2014) 319-337

44. Bock, A.: The concepts of decision making: An analysis of classical approaches and avenues for the field of enterprise modeling. In Ralyté, J., España, S., Pastor, Ó., eds.: The Practice of Enterprise Modeling. Volume 235 of LNBIP. Springer, Heidelberg and New York (2015) 306-321

45. Berger, P.L., Luckmann, T.: The social construction of reality; A treatise in the sociology of knowledge. Doubleday, Garden City (1966)

46. Bock, A.: How modeling language shapes decisions: Problem-theoretical arguments and illustration of an example case. In Schmidt, R., Guédria, W., Bider, I., Guerreiro, S., eds.: Enterprise, Business-Process and Information Systems Modeling. Volume 248 of LNBIP. Springer, Heidelberg and New York (2016) 383-398

47. Frank, U., Strecker, S.: Beyond ERP Systems: An Outline of Self-Referential Enterprise Systems. ICB Research Report 31, Univ. Duisburg-Essen, Essen (2009) 